\title{
Gazi Üniversitesi Merkez Kütüphanesi: Bilgiyi Hayata Dönüştüren Kütüphane
}

\author{
Gazi University Central Library: The Library Transforms \\ from Information to Life
}

\section{Özden DEMiRcioĞLU*}

\begin{abstract}
Öz
Bu makalede, Gazi Üniversitesi Merkez Kütüphanesi'nin kuruluşu, gelişimi, verdiği hizmetler, derme yapısı, kullanıcı eğitimi ve gelecekteki hedefleri anlatılmaktadır.
\end{abstract}

Anahtar sözcükler: Gazi Üniversitesi Merkez Kütüphanesi, Üniversite kütüphaneleri, Kütüphane tanıtımı, Kütüphane hizmetleri.

\section{Abstract}

The present paper describes the Gazi University Central Library, and its foundation, development, nature of services, collections, user training and future aims.

Keywords: Gazi Universitesi Central Library, University libraries, Library publicity, Llibrary services.

\section{Giriş}

Bir ülkenin araştırma ve eğitim kurumlarının başında gelen üniversiteler, ülkenin gelişmesine ürettikleri bilimsel bilgi ile katkıda bulunurlar.

Üniversitelerin amaçları genel olarak şu şekilde ifade edilebilir:

$>\quad$ Toplumun, bilimsel, teknik ve kültür düzeyini yükseltmek,

$>\quad$ Toplumun intiyaç duyduğu nitelikte insan yetiştirmesini sağlamak,

$>$ Yaratıcı ve araştırıcı niteliklere sahip öğrenciler yetişmesini sağlamak,

$>\quad$ Hizmetinde bulunduğu toplumun ortak kültür ve yaşam seviyesini yükseltmek (Çakın, 1983, s. 61).

" Okutman; Gazi Üniversitesi Kütüphane ve Dokümantasyon Daire Başkanlığı Danışma Bölümü Rektörlük Kampusu 06500 Teknikokullar Ankara (ozdend@gazi.edu.tr). 
Üniversiteler bu amaçlarını yerine getirebilmek için kütüphanelere gereksinim duyarlar. Gazi Üniversitesi Merkez Kütüphanesi de, bünyesinde yer aldığı Gazi Üniversitesinin amaçlarını ve faaliyetlerini gerçekleştirebilmesi için gerekli olan bilimsel yayınları toplamakta, düzenlemekte, duyurmakta ve araştırmacılarına sunmaktadır.

1982 tarih ve 2809 sayılı yasa ile kurulmuş olan Gazi Üniversitesi (2007); 14 fakülte, 5 yüksekokul, 9 meslek yüksekokulu, 35 araştırma merkezi ve 5 enstitüden oluşmaktadır. Merkez Kütüphane, aynı yıl üniversitenin İktisadi ve İdari Bilimler Fakültesi'nin bahçesinde bulunan $2000 \mathrm{~m}^{2}$ lik binasında hizmet vermeye başlamıştır. Hizmetlerini 27 Mayıs 2004 tarihinden itibaren, üniversitenin Rektörlük Kampusu içinde bulunan $11.000 \mathrm{~m}^{2}$ lik yeni binasında vermeye devam etmektedir (Gazi Üniversitesi Merkez Kütüphanesi (2007).

Merkez Kütüphane, 50 bini aşan öğrenci ve 3 bini geçen öğretim elemanı sayısıyla (Gazi Üniversitesi 2007); öğrenci başına düşen öğretim elemanı sayısında dünya ortalamasını yakalayabilmiş bir üniversitenin kütüphanesidir. Kütüphane, üniversitenin bilimsel üretkenliği ile de dünya ortalamasını yakalamak için eğitim - öğretim ve araştırma faaliyetlerini desteklemekte, araştırmacıların bilgi gereksinimlerini eksiksiz ve hızlı bir şekilde güncel kaynaklardan karşılamaya çalışmaktadır

\section{Kütüphane Hizmetleri}

Gazi Üniversitesi Merkez Kütüphanesi, bir üniversite kütüphanesinin yapması gerektiği gibi "bilgi kaynaklarının etkin bir şekilde kullanımını artıracak ödünç verme, danışma, enformasyon ve diğer hizmetleri yerine getirerek bunun yanında bibliyografik kaynak ve araçları hizmete sunar" (Çelik ve Uçak, 1993).

Kütüphane dermesini oluşturan bilgi kaynakları, Gazi Üniversitesi'nin akademisyenlerinin ve öğrencilerinin bilgi gereksinimleri doğrultusunda, çeşitli bölümlerdeki öğretim üyelerinin görüşleri alınarak uzman kütüphaneciler tarafından seçilir. Derme oluşturma ve geliştirme işlemleri, diğer hizmetlerde olduğu gibi, kütüphaneci ile kullanıcının işbirliğiyle yürütülür. $\mathrm{Bu}$ süreç, kütüphanenin derme geliştirme politikasına bağlı olarak, verilen bütçe miktarına göre geliştirmektedir.

Merkez Kütüphane, üniversite yönetiminin de desteğini alarak, bilgi hizmetlerini kullanıcılarına sunmaktadır. Çünkü kütüphanenin gereksinimleri, bilinçli olarak oluşturulan bütçe ve derme politikasına 
göre belirlenmesinin yanı sıra, çok iyi yıllık tahminler yapılmakta ve üniversite yönetimine bütçe önerisi sunulmaktadır.

2005 yılında yurtdışı ve yurtiçi olmak üzere kütüphanemize harcanan bütçe 2.290.209,73 YTL olup; bütçenin dağılımı şöyledir:

Abone: 637.015,83 YTL

Elektronik: $662.430,56$ YTL

Kitap: 973.029,49 YTL

Görüntülü Yayınlar: 17.683, 85 YTL

2006 yılında ise kütüphaneye ayrılan bütçe 2 Milyon YTL olmuştur.

Bir devlet üniversitesi kütüphanesi olarak niceliksel ve niteliksel anlamda iyi ve kaliteli kaynaklara sahip olan kütüphanenin 2006 yılsonu itibariyle derme durumu aşağıdaki gibidir:

- 167.849 adet kitap

- 11.819 adet yüksek lisans ve doktora tezi

- 46.232 adet kitap dışı materyal

- 709 adet yabancı süreli yayın

- 612 adet Türkçe süreli yayın

- 64.649 adet ciltli dergi

- 24.013 adet elektronik dergi

- 32.000 adet elektronik kitap

- 2.800 .000 elektronik tez

- 25 adet tam metin,

- 10 adet bibliyografik metinli olmak üzere toplam 35 adet çevrimiçi veri tabanı.

Kütüphane dermesine her yıl 10.000 ila 15.000 civarında eklenen yayınlar MARC21 formatına göre çevrimiçi kataloga aktarılmaktadır. BLISS Kütüphane Otomasyon Sisteminin tercih edildiği kütüphanede Sosyal Bilimler-Fen-Teknoloji alanındaki kitaplar için Library of Congress (LC) Sınıflama Sistemi ve konu başlıkları (LCSH), Sağlık Bilimleri (TıpDiş hekimliği- Eczacılık) alanındaki kitaplar için de National Library of Medicine (NLM) Sınıflama Sistemi ve konu başlıkları (MeSH) kullanılmaktadır. Ayrıca konu başlıklarının Türkçeye uyarlanmış karşılıkları da verilmektedir. Gazi Üniversitesi Kütüphanesi, bu konuda Türkiye'de ilk çalışma yapan öncü kütüphanelerinden biridir.

Personelin, kütüphanelere işlevlik kazandırdığını ve kaliteli hizmet verebilmesinde önem taşıyan en önemli unsur olduğu farkındalığıyla hizmetlerini gerçekleştiren Gazi Üniversitesi Merkez 
Kütüphanesi'nde kullanıcı memnuniyeti her şeyden önce gelmektedir. Halkla ilişkilerin ön planda tutulduğu kütüphanede 1 daire başkanı, 13 uzman, 2 okutman, 24 memur olmak üzere toplam 40 personel bulunmaktadır. Ayrıca burs karşılığında çalışan 73 yarı zamanlı öğrenci vardır.

Gazi Üniversitesi Merkez Kütüphanesi, bilgiye gereksinim duyan kullanıcılarının mekândan ve zamandan bağımsız olarak bilgiye erişmelerini sağlar. $\mathrm{Bu}$ amaçla danışma hizmeti kapsamında, kullanıcılara kütüphane hakkında genel bilgi verme, katalog sorgulama terminallerinin kullanımı ve aradıkları bilgilere ulaşabilmeleri için uygun birime veya kaynağa yönlendirme yapılmaktadır. Aynı zamanda basılı ve elektronik yayınlar yakından izleyerek bilimsel araştırma sonuçları araştırmacılara ulaştırılmaktadır. Bunun için danışma kütüphanecileri sürekli kendini geliştirmekte, yenilikleri güncel olarak izlemekte ve verdiği hizmetleri çağın gereklerine uygun hale getirmektedir. Kütüphanenin diğer bir işlevi, araştırmacılarının kendi bilimsel çalışmalarını, bilim dünyasına duyurmak için köprü görevi yapmaktır. Bu amaçla, Gazi Üniversitesi akademisyenlerine ait atıflar Danışma Bölümü tarafından sürekli olarak izlenmekte, güncellenmekte ve web sayfasından duyurulmaktadır. Yapılan araştırmalara göre, dünyada 2001 yılında toplam 1 milyon 58 bin yayın üretilirken, 24. sırada olan Türkiye'nin, üretilen bilimsel yayınlara katkısının binde 6 oranında olduğu ortaya çıkmıştır (Ak ve Gülmez, 2004). 2006 yılında ülkeler arasında Web of Science'daki yayın sıralamalarında Türkiye, 178 ülke arasında 3450 yayın sayısıyla 18. sırada yer almıştır. Türkiye'deki üniversiteler arasındaki sıralamada ise, Gazi Üniversitesi 2005 yılında yayınladığı 777 makale ile 4. sırada yer alırken, 2006 yılının ilk 6 ayında 154 makale sayısıyla yine 4. sıradaki yerini korumaya devam etmiştir (TÜBiTAKULAKBIM, 2005).

Bir üniversite kütüphanesinin işlevleri arasında olması gereken "kullanıcı eğitim programları hazırlamak ve düzenlemek" görevi Danışma Bölümü tarafından yerine getirilmektedir. Web sayfasında yer alan kullanıcı eğitimi istek formu, telefon ve e-posta aracılığıyla iletilen istekler doğrultusunda kütüphane ile ilgili her türlü bilgilendirme ve kullanıcı eğitimi verilmekte, ayrıca çeşitli fakültelerde ve yüksek okullarda kredili ders olarak yer almaktadır. Teorik ve uygulamalı olarak hazırlanan eğitim ile öğrencilere kütüphane kullanım alışkanlığı ve bilgi okuryazarlığı kazandııımaya çalışılmaktadır. Aşağıda sıralandığı gibi fakültelere göre bu derslerin adları ve içerikleri değişebilmektedir: 
$>\quad$ Tıp Fakültesi - "Kanıta Dayalı Tıp" (Teorik / Pratik)

> Hemşirelik Bölümü - "Tıp ve Sağlık Bilimlerinde Bilgi Erişim" (Teorik / Pratik)

$>$ Eczacilık Fakültesi - "Kütüphane Web Sayfası ve Veri Tabanları Kullanımı" (Pratik)

> Sağlık Hizmetleri Meslek Yüksekokulu - "Tıp Kütüphaneciliği” (Teorik / Pratik)

Verilen derslerin yanı sıra kullanıcı eğitimine yönelik olarak, abone olunan "tüm" veri tabanlarının ve kütüphane web sayfasının kullanım ile ilgili kılavuzlar hazırlanarak web sitesi üzerinden kullanıcılara sunulmuştur.

Danışma ve tez gibi kütüphane dışına çıkarılmayan kaynaklar dışındakiler ödünç verme hizmeti ile kullanıcılara belli sürelerle verilebilmektedir. Belirlenen ödünç verme kurallarına göre, akademik personel 20 kitabı 2 ay, lisans öğrencileri 4 kitabı 15 gün, doktora ve yüksek lisans öğrencileri 6 kitabı 1 ay, idari personel ise 4 kitabı 15 gün süreyle ödünç alabilirler. 2006 yılı içerisinde 3440 akademik personel, 21.528. öğrenci, 510 idari personel olmak üzere toplam 25.478 kullanıcı ödünç verme hizmetinden yararlanmıştır.

Kütüphane, bilginin ve bilgi paylaşımının evrensellik ilkesine uyarak, diğer bilgi merkezleri ve kütüphaneler ile işbirliği yapmaktadır. 2006 yılında işbirliği kapsamında yurt içinden gelen istekler yanında Amerika Birleşik Devletleri, Macaristan, Japonya'ya da kitap ve makale istekleri ulaştııılmıştır (Demircioğlu ve Dizman, 2006).

Merkez Kütüphanede olması gereken temel okuyucu hizmetlerinin yanı sıra görme engelliler için hazırlanan "Braille Salonu"nda, iki adet konuşan bilgisayar, birer adet Braille alfabesiyle çıktı alınabilen yazıcı ve Latin Alfabesini Braille Alfabesine çeviren yazıcı bulunmaktadır. Ayrıca kullanıcıların boş zamanlarında, görsel öğrenme ve dil öğrenme becerilerine katkıda bulunmak amacıyla kullanabilecekleri 20 adet LCD ekran bilgisayarın bulunduğu "Multimedia" bölümü oluşturulmuştur. Gazi Üniversitesi'nde yapılmış yüksek lisans ve doktora tezleri "Tez Odası"nda, basımı tükenmiş kaynaklar, nadir eserler ve sanat kaynakları "Kapalı Oda"da kullanıma sunulmaktadır.

Kütüphanenin alt katında, bilişim teknolojileri donanımına sahip 143 kişilik "Konferans Salonu" da çeşitli etkinliklerde kullanılmaktadır. Bunun yanı sıra öğrenciler için sesli olarak da çalışabilecekleri 3 adet 
"Grup Çalışma Odası", akademisyenler için 28 adet çalışma bölmesi (karel) bulunmaktadır. Öğretim elemanlarına sağlanan bir diğer kolaylık, saatlik olarak kütüphane içinde kullanım için kimlik karşıı̆̆ı verilen 5 adet diz üstü bilgisayarın olmasıdır.

Bunların dışında Kütüphane, Üniversitenin kültürel gelişimine katkıda bulunmak için oluşturulan "Somut Olmayan Kültürel Miras Müzesi”ne de ev sahipliği yapmaktadır.

Merkez Kütüphane bilgi teknolojisi alt yapısını sürekli yenileyerek, bilgi intiyacı duyan araştırmacıların bilimsel alandaki literatüre ve yapılan çalışmalara hızlı ve doğru bir şekilde ulaşmalarını sağlayarak araştırma sürecini kısaltmaktadır. Buna bağlı olarak kullanıcılarına 29 adet bilgisayardan çevrimiçi katalog taraması için olanak sağlarken, 200 bilgisayar kapasitesi ve kablosuz İnternet bağlantısına sahip laboratuvarı ile elektronik ortamdaki güncel bilgiyi sunmaktadır.

Açık erişim anlayışı, yapılan araştırma sonuçlarına İnternet ortamından ücretsiz olarak erişimin sağlanması ve bilginin paylaşımını (ANKOS, 2006) hedeflemektedir. Gazi Üniversitesi Merkez Kütüphanesi, araştırmacılarının yayın yaptığı (abone olsun ya da olmasın) dergilere, konferans bildirilerine, tezlere ve araştırma raporlarına İnternet üzerinden ücretsiz olarak erişimi sağlayan açık erişimi desteklemekte ve bu konuda kullanıcılarını bilgilendirmeye çalışmaktadır. Bu amaçla araştırmacıların yayınlarını açık erişimli dergilere veya açık erişim arşivlerine göndermeleri için yönlendirmektedir. Ayrıca Bilgi İşlem Daire Başkanlığı ve Kütüphane ve Dokümantasyon Daire Başkanlığı işbirliği ile Gazi Üniversitesi adına bir açık erişim yazılım programı oluşturularak çalışmalarına başlanılmıştır.

\section{Sonuç}

Gazi Üniversitesi Merkez Kütüphanesi sahip olduğu yapısal unsurlarla, kullanıcılarına kütüphaneci-kullanıcı işbirliğine dayalı kaliteli ve güler yüzlü hizmet vererek üniversitenin temel yapılarından birisi olmuştur. Bunun yanı sıra, üniversitenin eğitim-öğretim faaliyetlerini desteklemek, yaratıcı ve araştırıcı öğrencilerin yetiştirilmesine katkı sağlamak ve üniversite mensuplarının kültür düzeyini yükseltecek çalışmalarda bulunmak olan amaçlarını da korumayı hedeflemektedir.

Üniversitenin ilkesi olan "Bilgiyi hayata dönüştürür" ilkesini benimseyen Merkez Kütüphane, basılı kaynakların temininin yanı sıra, bilgi kaynaklarına elektronik ortamdan da erişim için, günümüz 
şartlarında yeterli olan teknolojik alt yapısının yardımıyla zaman ve mekândan bağımsız olarak bilgiye hızla erişimi sağlamaya çalışmaktadır.

\section{Kaynakça}

ANKOS. (2006). Bilimsel bilgiye erişimdeki engelleri kaldırmak elinizde! 2 Ekim 2006 tarihinde ANKOS Web sitesinden erişildi: http://www.ankos.gen.tr/acikerisim/AcikerisimWEB.pdf

Ak ve Gülmez (2004, 25-26 Kasım). Atıf indekslerine göre Türkiye'nin bilimsel yayın performansının analizi: 1980-2003. III. Ulusal Bilgi, Ekonomi ve Yönetim Kongresi. 28 Eylül 2006 tarihinde http://iibf.ogu.edu.tr/kongre/bildiriler/12- 04.pdf adresinden erişildi.

Çakın, İ. (1983). Üniversite-kütüphane ilişkisi. Türk Kütüphaneciler Derneği Bülteni, 32, 61-64.

Çelik, A ve Uçak, N. (1993). Üniversite kütüphaneleri üzerine. Hacettepe Üniversitesi Edebiyat Fakültesi Dergisi, 10, 115-121.

Demircioğlu, Ö. ve Dizman, N. (2006). Gazi Üniversitesi Merkez Kütüphanesi sunumu. ÜNAK'06 Bilimsel İletişim ve Bilgi Yönetimi Konferansı, Ankara. 12-14 Ekim 2006.

Gazi Üniversitesi. (2007). Tarihçe. 9 Mart 2007 tarihinde Gazi Üniversitesi web sitesinden erişildi: http://www.gazi.edu.tr/ tarihce.php

Gazi Üniversitesi Merkez Kütüphanesi. (2007). 2 Mart 2007 tarihinde http://www.lib.gazi.edu.tr/kuttan.html adresinden erişildi.

TÜBITAK-ULAKBIM. (2005). Web of Science Atıf İndeksleri Yayın Sıraları (Mayıs 2006). 2 Ekim 2006 tarihinde ULAKBIM web sitesinden erişildi: http://arama.ulakbim.gov.tr/wos/ index.php? Yil $=2006 \&$ Index $=$ ALL\&Tip $=1 \&$ command $=G \% F 6$ ster\& cwid $=2 \&$ orde $r=2 \& A$ IIInOnePage $=$ 